Divers@ Revista Eletrônica Interdisciplinar,

Matinhos, v. 13, n. 2, p. 142-153, jul./dez. 2020

ISSN 1983-8921

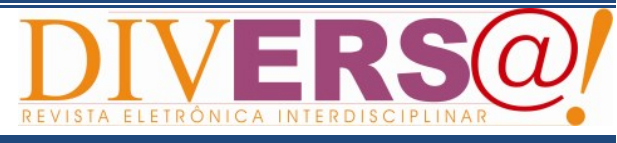

\title{
ATERRO SANITÁRIO: RELEVÂNCIA E TÉCNICAS DE IMPERMEABILIZAÇÃO DO SOLO
}

\section{LANDFILL: RELEVANCE AND SEALING TECHNIQUES}

\author{
Alex Air Santiago Junior ${ }^{1}$ \\ Simone Beatriz Fuck Von Der Osten ${ }^{2}$ \\ Eduardo Henrique Von Der Osten Junior ${ }^{3}$ \\ Camila Ferreira Miyashiro ${ }^{4}$ \\ Erich dos Reis Duarte ${ }^{5}$ \\ Aline Vanessa Sauer ${ }^{6}$
}

\begin{abstract}
Resumo
O objetivo deste artigo é mostrar a importância da impermeabilização adequada em aterros sanitários e as principais técnicas de impermeabilidade para evitar a contaminação do solo e do lençol freático. A metodologia adotada baseou-se em pesquisa bibliográfica. $\mathrm{O}$ aterro sanitário é um processo utilizado para disposição final de rejeitos e resíduos sólidos no solo, particularmente lixo domiciliar. A impermeabilização do solo tem a função de proteger e impedir a infiltração do chorume, líquido originado dos processos biológicos, químicos e físicos da decomposição de resíduos orgânicos, para o subsolo e aquíferos existentes. Entre todos os aspectos que precisam ser conferidos em um aterro sanitário, desde o preparo da área e construção até sua operação e monitoramento, ressalta-se o sistema de impermeabilização de base. Em locais onde o solo não apresenta as características necessárias ao emprego de barreira impermeabilizante, é utilizado o acréscimo de bentonita ao solo. Em conjunto com a aplicação da camada impermeabilização e fundação do aterro, são introduzidos sistemas para drenar os líquidos. Diante disso, o presente trabalho discutiu em seus resultados as técnicas de permeabilidade como Liners utilizados em aterros sanitários, Lodo aplicado como camada de cobertura, Resíduos de construção e demolição (RCD) aplicados como camada de cobertura, Barreira capilar aplicada como camada de cobertura, Solo compactado aplicado como camada de cobertura e impermeabilização de base, Geossintéticos aplicados como camada de impermeabilização de base, Solo cimento aplicado como impermeabilização de base e Bentonita aplicada como impermeabilização de base.
\end{abstract}

Palavras-chave: Geomembranas; proteção do solo; chorume.

\footnotetext{
Artigo Original: Recebido em 30/09/2020 - Aprovado em 14/10/2020.

${ }^{1}$ Engenheiro Agrônomo pela Universidade Pitágoras Unopar, Bandeirantes-PR.e-mail: alexairjr@hotmail.com

${ }^{2}$ Mestre em Agronomia pela Universidade Estadual de Londrina, Londrina-PR.e-mail: simonebeatrizosten@hotmail.com

${ }^{3}$ Graduando em Agronomia na Universidade Pitágoras Unopar, Bandeirantes-PR. e-mail: ostenjr2006@hotmail.com

4 Docente de Graduação em Agronomia, Universidade Pitágoras Unopar e Universidade Estadual Norte do Paraná, Bandeirantes-PR.e-mail: camila.ferreira@kroton.com.br

5 Docente de Graduação em Agronomia, Universidade Pitágoras Unopar, Bandeirantes-PR. e-mail: erich.r.duarte@educadores.net.br

${ }^{6}$ Docente de Graduação em Agronomia, Universidade Pitágoras Unopar. Docente do Programa de Pós Graduação Stricto Sensu em Agronomia na Universidade Estadual Norte do Paraná, Bandeirantes-PR. e-mail: aline.sauer@kroton.com.br (autor correspondente).
} 


\section{Abstract}

The purpose of this article is to show the importance of waterproofing in landfills and the main waterproofing techniques to avoid contamination of soil and groundwater. The adopted methodology was based on bibliographic research. The landfill is a process used for the final disposal of waste and solid waste in the soil, particularly household waste. A waterproofing of the soil has the function of protecting and preventing the infiltration of leachate, a liquid originated from biological, chemical and physical processes of decomposition of solid waste, into the existing subsoil and aquifers. Among all the aspects that need to be checked in a landfill, from the preparation of the area and construction to its operation and monitoring, the basic waterproofing system stands out. In places where the soil does not have areas restricted to the use of waterproofing barrier, the addition of bentonite to the soil is used. In conjunction with the application of the waterproofing layer and the foundation of the landfill, systems are introduced to drain liquids. Therefore, the present work discussed in its results how permeability techniques such as Liners used in landfills, Sludge applied as a covering layer, Construction and demolition waste (RCD) required as a covering layer, Capillary barrier applied as a covering layer, Compacted soil applied as a covering layer and base waterproofing, Geosynthetics applied as a base waterproofing layer, Soil applied as a base waterproofing and Bentonite applied as a base waterproofing.

Keywords: Geomembranes; soil protection; leachate.

\section{Introdução}

O lixo disposto de forma inadequada e sem tratamento, pode poluir o solo e alterar suas características físicas, químicas e biológicas (LIMA, 1985).

O aterro sanitário é um processo utilizado para disposição final de rejeitos e resíduos sólidos no solo, particularmente lixo domiciliar. É uma obra de engenharia projetada sob critérios técnicos, seguindo a legislação ambiental específica que tem como objetivo evitar danos à saúde pública, solo, água e ao ambiente em geral. A impermeabilização do solo tem a função de proteger e impedir a infiltração do chorume, líquido originado dos processos biológicos, químicos e físicos da decomposição de resíduos orgânicos, para o subsolo e aquíferos existentes (WORKMAN; KEEBLE, 1989). No Brasil, existem exigências legais e ambientais quanto a contenção de lixiviados nas camadas de fundo e laterais do aterro sanitário com geomembranas de polietileno de alta densidade (PEAD), recomendada pela segurança e durabilidade comprovada na diminuição dos impactos ambientais (LANZA, CARVALHO, ALVIM, 2005).

A drenagem dos lixiviados é executada através de uma rede de drenos internos que levam o chorume para um sistema de tratamento diferente do que ocorria com os antigos lixões, o qual impede a contaminação do solo e do lençol freático (LIMA, 1985; WORKMAN; KEEBLE, 1989).

Este trabalho de pesquisa tem como objetivo demonstrar a importância da impermeabilização adequada em aterros sanitários, identificar os tipos de impermeabilização permitidas e aplicação das técnicas de impermeabilidade. $O$ trabalho foi desenvolvido através de pesquisa bibliográfica embasada em livros, artigos de especialistas no assunto, monografias e teses, relatórios, revistas, periódicos, entre outras fontes de dados.

\section{Impermeabilização de solo}

A gestão de resíduos sólidos urbanos (RSU) é uma necessidade diária e consideram-se os aterros sanitários os destinos mais adequados para a disposição desses resíduos. Entre as estruturas que constituem os aterros sanitários estão as barreiras impermeabilizantes de base que podem ser de vários tipos, porém as constituídas por solo argiloso compactado são amplamente utilizadas (LEME, 2013).

Dentre todos os aspectos que precisam ser conferidos em um aterro sanitário, desde o preparo da área e construção até sua operação e monitoramento, ressalta-se o sistema de 
impermeabilização de base. $\mathrm{O}$ sistema impermeabilizante de base tem como objetivo a proteção ao ambiente contra os contaminantes que são gerados pelos líquidos dos resíduos ali depositados, denominados chorume ou lixiviados. Estes resíduos são capazes de atingir solos, águas subterrâneas e de superfícies adjacentes ao local de disposição (LEME, 2013).

Segundo Piedade Júnior (2003), o sistema impermeabilizante de base pode ser composto por materiais naturais ou sintéticos e sofrer grandes influências das características dos resíduos e da área de contorno, como as condições de clima e de geologia. Mesmo que os mecanismos artificiais comprovem sua funcionalidade e praticidade, são considerados como de custo elevado, geralmente ultrapassando o orçamento do município. Dessa maneira, os meios naturais de impermeabilização de base de aterros sanitários mostram-se com maior vantagem em relação a custo-benefício.

Os materiais naturais para finalidade de uso em sistemas impermeabilizantes de base com características intrínsecas (geológicas) e/ou de compactação precisam ser analisados com cuidado, a fim de assegurar as funções da barreira. É essencial também que a demanda de materiais naturais esteja localizada relativamente próxima ao local da concepção do sistema de impermeabilização de base, visando o menor custo de transporte do material natural (PIEDADE JUNIOR, 2003).

A camada de cobertura de solo compactado tem a função de controlar à entrada de água e ar para dentro do aterro; minimizar a migração dos gases gerados para a atmosfera; servir como elemento de redução de odor; vetores de doença e facilitar a recomposição da paisagem (CATAPRETA, 2008). Já em relação à camada de base, a utilização impede que os líquidos resultantes do processo de biodegradação dos RSU, denominados de lixiviados, percolem e contaminem o lençol freático e as demais camadas de solo (MACIEL; JUCÁ, 2003).

Estão em vigor a NBR 13896/1997, que trata da apresentação de projetos de aterros sanitários de RSU e a NBR 15849/2010, que trata dos critérios para projeto, execução e implantação de aterros. As regulamentações da Agência de Proteção Ambiental Americana (EPA), como a EPA (2004) e a EPA (2011), fornecem orientações sobre práticas operacionais em aterros sanitários, bem como contribuem para a melhoria dos procedimentos padrão dos aterros.

A impermeabilização de base de aterro sanitário pode ser considerada simples quando formada por apenas um elemento de impermeabilização e dupla ou composta quando é executada revezando as camadas de solo natural e geomembrana, por exemplo. O tipo de impermeabilização de base leva em consideração a composição química do lixiviado, o coeficiente de permeabilidade do meio e da economia com relação ao empréstimo de material natural. Os tipos mais usados e citados nas literaturas são as barreiras de argilas naturais, as barreiras de solos argilosos compactados e as barreiras compostas por materiais sintéticos (PIEDADE JÚNIOR, 2003). Para a impermeabilização do aterro é importante que sejam realizados testes a campo e em laboratório para testar a validade do material argiloso. Os resultados destes testes permitem aos profissionais avaliarem a adequação do material argiloso utilizado no processo de impermeabilização do aterro e a certificação dos materiais utilizados como barreiras minerais (BARBERO; MARONI; PEYROT, 2020).

São inúmeras as vantagens do método de aterro sanitário e seu baixo custo torna esta prática ainda mais interessante (LIMA, 1985). O fundo do aterro é coberto por uma camada de argila compactada, e em alguns casos com uma camada extra de material plástico, a fim de que seja promovida a sua impermeabilidade e previna a infiltração do chorume no solo. Poços de coleta e bombeamento do chorume gerado também podem ser adicionados ao fundo do aterro. O lixo situado no aterro é coberto periodicamente por uma camada de solo, formando células. Tubulações verticais são inseridas com o intuito de coletar os gases produzidos pela decomposição do material (LIMA, 1985; MIMIDES; PERRAKI, 2000).

Em locais onde o solo local não apresenta as características necessárias ao emprego de barreira impermeabilizante, é utilizado o acréscimo de bentonita para que sejam atingidas as propriedades necessárias. A mistura de bentonita ao solo local para transformar a camada em impermeabilizante de base de um aterro de resíduos, está ligada principalmente ao coeficiente de condutividade hidráulica que esta camada irá apresentar. Sobretudo 
ao custo que aplicar esse tipo de impermeabilizante irá exigir, quando comparado com a importação de solo argiloso de jazida externa à obra (LUKIANTCHUKI; ESQUIVEL, 2006).

De acordo com Rowe (2000) a proporção considerada correta para a mistura de bentonita com solo está entre 4 a $10 \%$ e os valores de condutividade hidráulica entre $10-7$ a $10-9 \mathrm{~cm} / \mathrm{s}$. Portanto, é necessário estabelecer uma proporção de bentonita e teor de umidade para cada caso. Para isso são realizadas misturas de solo, em diversas proporções de bentonita e teor de umidade, analisando-se em laboratório os valores de condutividade hidráulica alcançados.

A diminuição do valor de condutividade hidráulica em uma mistura de solo-bentonita, se baseia no tipo de bentonita que adicionada e na proporção de material que será utilizado. No caso de areias com granulometria de fina a média, teores entre 3 a 4\% de bentonita sódica natural mostram declínio na condutividade hidráulica de duas ordens de magnitude (LUKIANTCHUKI; ESQUIVEL, 2006).

De acordo com Geofoco (2019) para a segurança da impermeabilização do aterro, deve-se observar as seguintes etapas para instalação:

1. Preparação do solo: o solo deve estar livre de materiais granulares, como pedriscos, raízes de árvores, dentre outros, que causem perfurações na geomembrana quando puncionada. Quando durante as escavações do terreno forem encontradas veias rochosas, o mesmo deverá ser previsto uma manta geotêxtil de alta gramatura sob a geomembrana para proteção mecânica.

2. Valeta de ancoragem: deve ser aberta ao redor da área a ser impermeabilizada uma valeta com pelo menos $50 \mathrm{~cm}$ afastada do topo do talude com profundidade mínima definida conforme projeto para ancoragem da geomembrana e, em seguida, preenchida com solo local.

3. Paginação da geomembrana: precisa ser realizada de maneira a aprimorar a obra na técnica e na economia, bem como moldar os cantos, de modo que proporcione melhor qualidade de solda.

4. Folga técnica: na instalação da manta é recomendado deixar folgas para evitar danos que a dilatação e contração provocam devido a intempérie. Quando o aterro sanitário for projetado com seções mistas de corte e aterro, evitar deformações que por acaso ocorram pela acomodação do solo ao ser subordinado à carga do depósito de material.

5. Acabamento final: nas tubulações de drenagem e coleta de líquidos os acabamentos precisam ser feitos em alto nível técnico. Há a necessidade da utilização de abraçadeiras de aço inox para que a corrosão seja evitada.

Segundo Locastro e Angelis (2016), entre os diversos elementos que existem para a proteção do solo destacam-se os que são responsáveis por realizar a impermeabilização do material e contenção de contaminantes dentro dos aterros. Entretanto, as barreiras de proteção foram criadas com o objetivo de impermeabilizar o solo, e estabelecidas ao todo diversos tipos de liners de acordo com fatores econômicos, grau de periculosidade dos resíduos e riscos ambientais.

Os liners utilizados com mais frequência são os geossintéticos, solos argilosos compactados, resíduos sólidos urbanos, geocomposto bentônico, solo cimento ou uma mistura de diferentes compostos. Pode-se ressaltar também que ainda existem outros tipos de liners com estudos em progresso que utilizam, por exemplo, tiras de pneus ou combinação de solos e cal hidratada como forma de barreiras impermeabilizantes (LOCASTRO; ANGELIS, 2016).

Os elementos de proteção dos aterros sanitários são definidos como estruturas que compõem os aterros, com o objetivo de permitir a disposição de resíduos sólidos urbanos em locais com exigência de áreas menores e garantia de segurança ao meio ambiente e à saúde pública (LOCASTRO; ANGELIS, 2016).

Conforme a Fundação Estadual do Meio Ambiente de Minas Gerais (FEAM, 2005) explica, estes elementos de proteção encontram-se distribuídos nos aterros através de sistema de cobertura, sistema de drenagem superficial; sistema de coleta e drenagem de líquidos percolados; sistema de tratamento de líquidos percolados; sistema de coleta e tratamentos dos gases e sistema de impermeabilização de base e laterais. 
Cada elemento que compõe o aterro tem sua finalidade dentro do sistema e, deste modo, auxiliam na etapa de operação e evitam danos indesejáveis. Os mecanismos de impermeabilização, por exemplo, trabalham para conter os resíduos contaminantes gerados e assim, diminuir os prejuízos ambientais que podem acontecer (LOCASTRO; ANGELIS, 2016).

\section{Importância da impermeabilização do solo}

A impermeabilização da fundação e das laterais do aterro tem como função a proteção e o impedimento da percolação do chorume para o subsolo e aquíferos. No Brasil, a exigência mínima para a contenção de lixiviados nãoperigosos é de que as camadas de fundo e laterais possuam uma camada simples, que pode ser de argila compactada de permeabilidade inferior a $10^{-7} \mathrm{~cm} / \mathrm{s}$ ou geomembranas de polietileno de alta densidade (PEAD) com espessura mínima de 1 mm. A qualidade do material e os métodos de construção devem assegurar durabilidade e segurança, no sentido de diminuir os impactos ambientais (ELK, 2007).

A poluição das águas subterrâneas e superficiais é um problema que precisa ser solucionado por meio da impermeabilização. Deste modo, é preciso dispor de elementos que possam dificultar a passagem destes líquidos através do solo. Uma das principais funções da impermeabilização de aterros sanitários é remover os líquidos lixiviados para fora do aterro, a fim de encaminhá-los para o sistema de tratamento adequado (TRÍGONO ENGENHARIA, 1999).

De acordo com a ABNT NBR 13896 (ABNT, 1997), é preciso impermeabilização do aterro sanitário quando as condições hidrogeológicas não estiverem de acordo com as seguintes especificações: depósito natural extenso e homogêneo com coeficiente de permeabilidade menor que $10^{-6} \mathrm{~cm} / \mathrm{s}$ e zona não saturada com espessura maior que 3 metros.

Essa norma mostra que o material da camada impermeabilizante precisa ser quimicamente compatível com os resíduos. Do mesmo modo, é preciso que possua espessura e resistência para que não haja rompimento devido as pressões hidrostáticas e hidrogeológicas, contato com o líquido lixiviado ou condições climáticas. $\mathrm{O}$ rompimento por assentamento, compressão ou levantamento do aterro também precisa ser evitado através do depósito da impermeabilização sobre uma base que tenha capacidade para suportá-la e tenha resistência aos gradientes de pressão. Outra orientação essencial é que a camada impermeabilizante esteja sob toda a base, para que se possa evitar o contato entre o solo e o líquido lixiviado (PAULA, 2017).

A ABNT NBR 13896 (ABNT, 1997) ainda determina que o desempenho do sistema de impermeabilização deve ser verificado durante todo o período em que o aterro esteja em atividade. Deste modo, é necessário que se tenha um sistema para deteç̧ão de vazamentos de lixiviados e, caso o vazamento aconteça, é preciso comunicar o órgão de controle ambiental, executar análises dos efluentes e iniciar a recuperação do sistema de impermeabilização que sofreu danos. De acordo com Workman e Keeble (1989),

\begin{abstract}
A permeabilidade do solo a ser utilizado em uma camada impermeabilizante é o fator mais importante para a determinação da eficiência a longo prazo. Solos argilosos com permeabilidade inferior a $10^{-7} \mathrm{~cm} / \mathrm{s}$ são comumente considerados adequados para fornecer proteção a longo prazo ao meio ambiente (WORKMAN; KEEBLE, 1989, p. 37)
\end{abstract}

A impermeabilização se baseia no conceito de aprisionar os resíduos através de barreiras impermeáveis, o que por consequência acaba protegendo os resíduos da entrada de líquidos externos e o subsolo da infiltração dos lixiviados e gases resultantes do aterro. Portanto, são utilizados como materiais impermeabilizantes, elementos sintéticos, do tipo geomembrana PEAD (VERTEMATTI, 2004).

A geomembrana é um dos materiais mais conhecidos de geossintéticos utilizados em obras que necessitem de prevenção ou bloqueio da influência de fluídos. Estes materiais podem ser líquidos ou gasosos, de saída ou entrada em um sistema. O mais usado em aterros sanitários é o PEAD (polietileno de alta densidade) que age como impermeabilizante do solo, protege mananciais e o lençol freático (VERTEMATTI, 2004). 
O princípio do aterro sanitário é controlar a migração de contaminantes para o meio ambiente por meio da contenção de resíduos, com a finalidade de evitar a poluição das águas de superfície e subterrâneas e do ar (BOSCOV, 2008). A contenção destes contaminantes pode ser realizada través do confinamento dos resíduos com solos compactados ou mantas geotêxteis. Solos argilosos compactados podem ser utilizados como material impermeabilizante em aterros sanitários nas camadas de base e cobertura (CARVALHO et al., 2015).
3.1 Aplicação da geomembrana em aterros sanitários

É possível notar na base e nas laterais do aterro a existência de georredes para drenar os lixiviados, geotêxtil para separar os resíduos e meio drenante (georrede ou material granular), geomembranas primárias e secundárias para proteger o solo de fundação e evitar que os líquidos lixiviados, originários da degradação dos resíduos ou através de infiltração, possam atingir o lençol freático ou águas superficiais (Figura 1) (VERTEMATTI, 2004; FELDKIRCHER, 2008).

Figura 1 - Aplicação típica de geossintéticos em aterros sanitários.

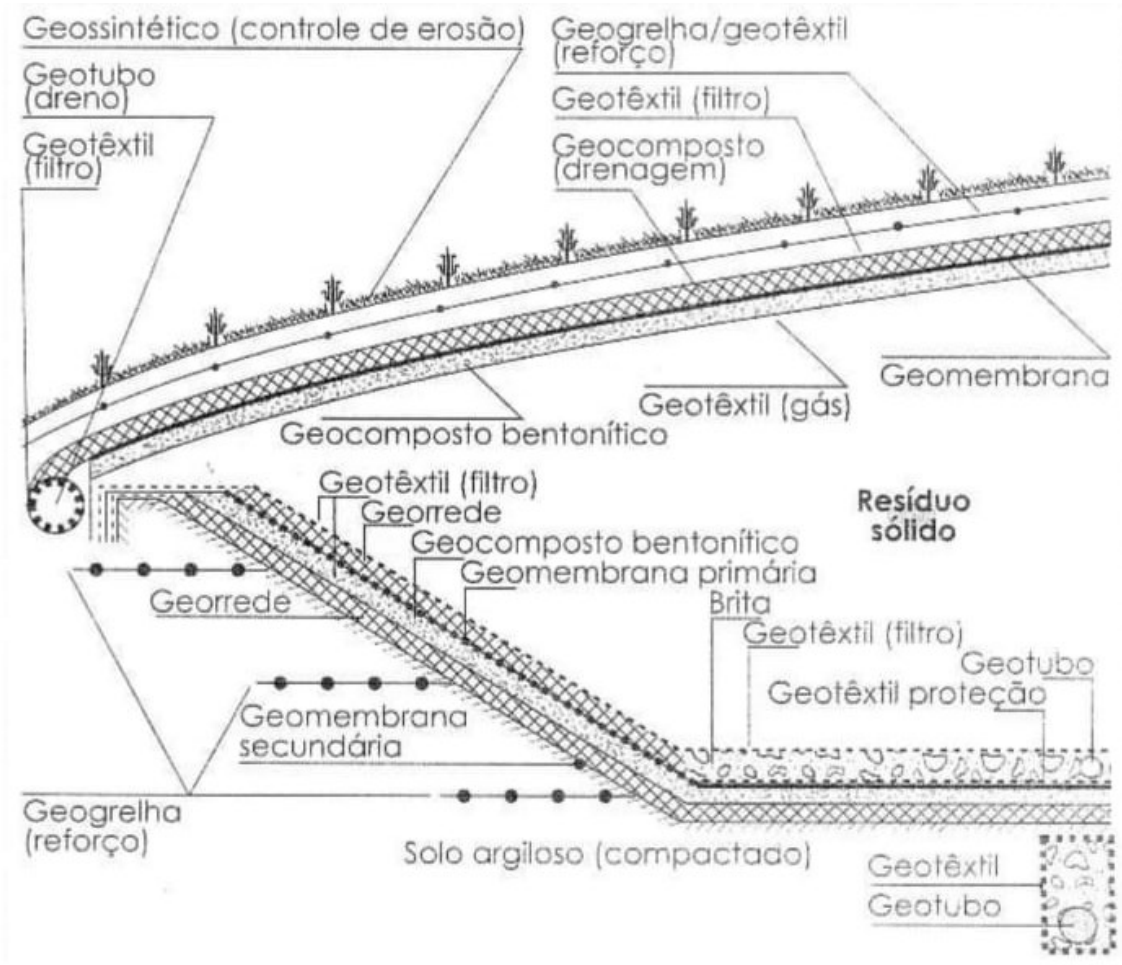

Fonte: adaptado de Feldkircher (2008).

Em geral, a geomembrana primária possui outra camada impermeabilizante, que é o geocomposto bentonítico, acompanhado de uma camada drenante para que seja possível detectar prováveis fugas, e finalmente, a geomembrana secundária colocada diretamente sobre o solo. Outro exemplo é a configuração de barreira impermeabilizante dupla, onde existem sistemas para detectar vazamentos e é muito usada na contenção de resíduos de maior periculosidade. Há também um sistema de cobertura do aterro, onde sua função é impedir que a água infiltre na parte maciça do aterro, o que evita o aumento do volume de lixiviados e que os gases derivados da decomposição desses resíduos se alastrem pela atmosfera (Figura 2) (FELDKIRCHER, 2008; ROWE, 2010). 
Figura 2 - Cobertura de aterro para melhoramento da captação do biogás.

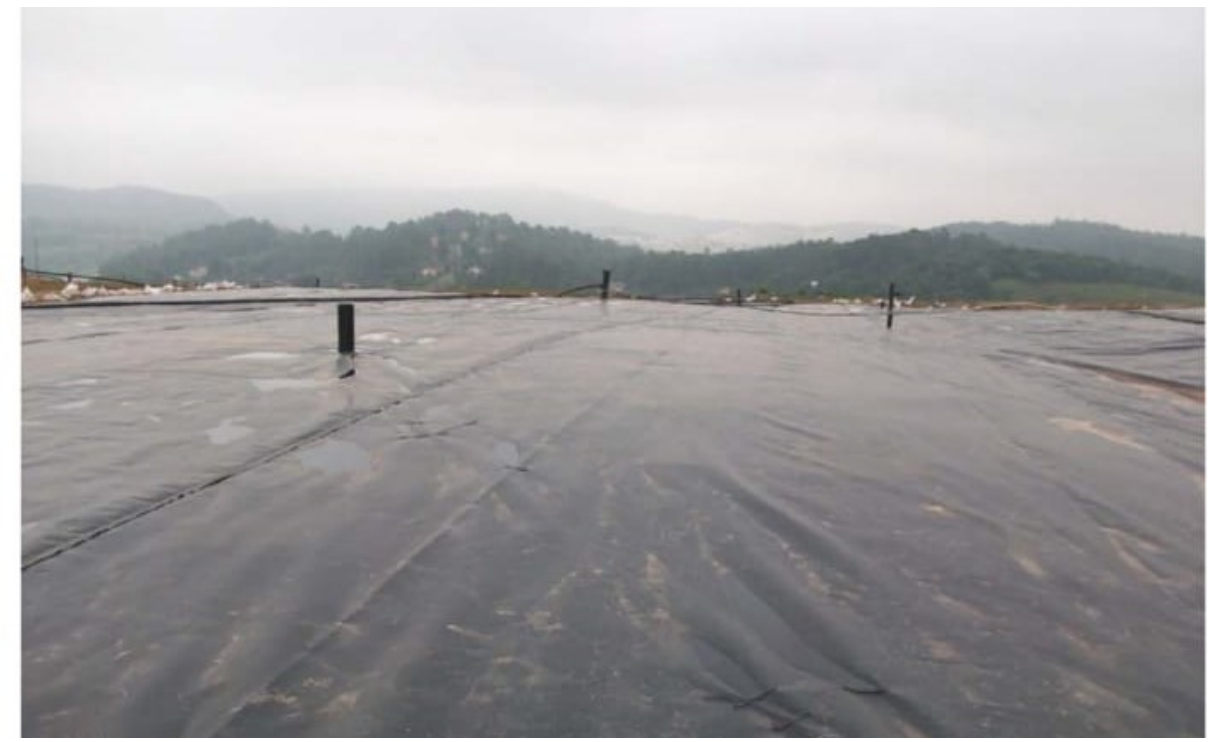

Fonte: adaptado de Feldkircher (2008).

Mesmo que as geomembranas sejam consideradas impermeáveis, elas estão susceptíveis a vazamentos, seja por defeito de fabricação, instalação incorreta ou equívoco na operação do sistema. Deste modo, é interessante adotar um sistema composto e com barreiras duplas para prevenir qualquer imperfeição, no qual o lixiviado será detectado logo na próxima barreira (FELDKIRCHER, 2008).

Em conjunto com a aplicação da camada impermeabilização e fundação do aterro, são introduzidos sistemas para drenar os líquidos que se constituem de linhas principais com tubos perfurados envolvidos com material granular subjacentes a camada drenante de areia ou brita, junto com os drenos secundários, de modo que se forme um sistema do tipo espinha de peixe. Os tubos podem ser de concreto ou PEAD. Os aterros de encostas, de modo geral, apresentam drenos de anel, os quais são executados junto à extremidade da escavação, mediante a execução de valas, as quais são preenchidas com material granular (FELDKIRCHER, 2008).

\section{Técnicas de impermeabilidade}

De acordo com Lins et al. (2008), para que os sistemas de impermeabilização sejam capazes de promover suas funções, é preciso que apresente algumas características que estão presentes em materiais de impermeabilização, como estanqueidade; durabilidade; resistência mecânica; resistência a intempéries e compatibilidade físico-químicobiológica com os resíduos a serem aterrados.

\subsection{Liners utilizados em aterros sanitários}

Segundo Carvalho (1999), os liners são dispositivos utilizados quando o desejo é a maior retenção possível dos líquidos ou para que seja evitada a entrada de água no aterro.

As barreiras de impermeabilização mais antigas usavam somente solos compactados em suas estruturas (LENGEN; SIEBKEN, 1996). Atualmente os sistemas de impermeabilização evoluíram e passaram a utilizar materiais como solo compactado, concreto, emulsões asfálticas, solo-cimento, membranas de bentonita, misturas de areia e bentonita, polietileno clorosulfurado (Hypalon), cloreto polivinílico (PVC), polietileno (PE), polietileno clorado e borracha butílica (BOFF, 1998).

Em relação à construção dos liners, não existe uma norma específica ou procedimento a ser seguido no país, mas pode-se recorrer a normas internacionais como o sistema europeu ou americano, desde que adaptados aos solos 
brasileiros. Independente do sistema construtivo escolhido, o liner a ser executado deve proporcionar qualidade e segurança, garantidos pela baixa permeabilidade e uma espessura mínima da barreira projetada (LOCASTRO; ANGELIS, 2016).

\subsubsection{Lodo aplicado como camada de cobertura}

O lodo decorrido de estações de tratamento de chorume pode ser usado como cobertura de aterros depois de um processo de compactação do material. De acordo com Bizarreta e Campos (2011) o composto é constituído basicamente por silte e após a secagem de 30 horas apresenta permeabilidade de $1,5 \times 10^{-5} \mathrm{~cm} . \mathrm{s}^{-1}$. O lodo forma trincas com facilidade e desta forma este sistema apresenta-se vantajoso pois além de proporcionar melhor aproveitamento do gás, também evita que gases como o metano escapem pelas frestas e atinjam a cobertura (BIZZARETA; CAMPOS, 2011).

\subsubsection{Resíduos de construção e demolição (RCD) aplicados como camada de cobertura}

Como método de reaproveitamento e disposição dos resíduos da construção é possível utilizar os RCDs na cobertura de aterros sanitários, o que diminui o contato direto do lixo com o ambiente externo. De acordo com Catapreta, Simões e Silveira (2011), os RCDs possuem compactação de aproximadamente $90 \%$, permeabilidade de $2,3.10^{-3} \mathrm{a}$ $5,9.10^{-3} \mathrm{~cm} . \mathrm{s}^{-1}$, com valores de umidade dentro do esperado. Os RCDs permitem a infiltração de uma parcela de água da chuva. No entanto, por causa de sua alta permeabilidade, auxiliam os lixiviados na percolação pelo maciço de resíduos e diminuem a formação de bolsões entre as camadas de resíduos (LOCASTRO; ANGELIS, 2016).

\subsubsection{Barreira capilar aplicada como camada de cobertura}

As barreiras capilares são sistemas de cobertura formados por materiais porosos que compõem uma camada de material fino sobre uma camada de material grosso. A compostagem é um exemplo desse tipo de sistema. Tem como finalidade a diminuição de infiltração de água da chuva pelo contraste entre os tamanhos das partículas. Considerando-se o rendimento, acumulam entre $81,6 \%$ a $93,4 \%$ do volume total de água (ALMEIDA; IZZO; MAHLER, 2011).

Esse sistema, assim como os liners de RCD diminuem a utilização de solos de áreas de empréstimo, o que torna o processo de construção da camada de cobertura mais barato e ambientalmente sustentável (ALMEIDA; IZZO; MAHLER, 2011).

Comumente, liners de polietileno de alta densidade (HDPE) são utilizados o objetivo de diminuir a contaminação de água subterrânea subjacente. Este tipo de membrana pode ser considerada um novo tipo de membrana reativa pulverizável em estruturas impermeabilizantes, pois em testes químicos, mecânicos e de durabilidade, demonstrou bom desempenho quando comparadas a membranas convencionais (SPAGNOLI et al., 2019).

4.1.4 Solo compactado aplicado como camada de cobertura e impermeabilização de base

Apesar de possuir maior permeabilidade do que os liners executados com geossintéticos ou combinação destes com solos, os liners feitos somente com solos compactados também são usados como impermeabilizantes e executam a função de barreiras de proteção (ALMEIDA; IZZO; MAHLER, 2011).

Algumas características do solo podem ter o desempenho melhorado como barreira quando se eleva a espessura ou aprimora a camada de compactação, o que reduz o número de vazios (ALMEIDA et al., 2010). Esse liner ainda possui como vantagem a diminuição dos custos, visando o uso de solos presentes nas proximidades do próprio aterro (ALMEIDA; IZZO; MAHLER, 2011).

\subsubsection{Geossintéticos aplicados como camada de impermeabilização de base}

O uso de geossintéticos como barreira impermeabilizante cresce a cada ano, devido a características como facilidade de construção, durabilidade, controle de qualidade e custo 
(BUENO; BENVENUTO; VILAR, 2004). Além disso, os materiais geossintéticos se constituem em importante aliados na preservação ambiental (VISENTIN et al., 2019).

As geomembranas são definidas como mantas poliméricas flexíveis com baixa permeabilidade, de aproximadamente $\quad 10^{-10} \quad \mathrm{~m} . \mathrm{s}^{-1} \quad$ (PIMENTEL; PALMEIRA, 2011), que são fabricadas a partir de PEAD (polietileno de alta densidade), PVC (polivinil clorado) e PELBD (polietileno linear de baixa densidade) (BUENO; BENVENUTO; VILAR, 2004).

Os geotêxteis protegem a geomembrana e evitam danos por puncionamento ou danos de perfuração por impacto. Podem atuar ainda como filtro em sistemas de drenagem ou de detecção de vazamentos. As georredes atuam como mecanismo de drenagem e podem ser utilizadas no sistema de detecção de vazamentos (PIMENTEL; PALMEIRA, 2011).

Para Rowe (2010) os GCL apresentam permeabilidade de $10^{-11} \mathrm{~m} \cdot \mathrm{s}^{-1}$ e podem ser uma alternativa à argila compactada. São constituídos basicamente por uma camada de bentonita confinada entre duas camadas de geotêxtil ou fixada a uma camada de geomembrana. A condutividade hidráulica dos GCL, consiste no parâmetro mais importante a ser avaliado em relação ao seu uso em aterros. A composição do lixiviado de aterros quanto à presença de cátions e ânions, também deve ser considerada, uma vez que esses compostos podem influenciar as características do GCL, como a condutividade hidráulica e também sua capacidade de troca catiônica (VISENTIN et al., 2019).

O coeficiente de permeabilidade nesses casos pode chegar a $10^{-12} \mathrm{~m} . \mathrm{s}^{-1}$ diminuindo a possibilidade de ocorrência de danos ambientais. A fim de obter sistemas mais restritivos ainda, pode utilizar configurações com dupla camada de geomembrana entremeada a solos compactados. Nessa situação o coeficiente de permeabilidade atinge níveis de cerca de $10^{-14} \mathrm{~m} \cdot \mathrm{s}^{-1}$ (ROWE, 2010).

\subsubsection{Solo cimento aplicado como impermeabilização de base}

Esse liner é o produto resultante da mistura íntima de solo, cimento portland e água compactados a um teor ótimo de umidade e sob a máxima densidade. Adquirem resistência e durabilidade por meio de reações de hidratação do cimento (ABNT, 1986).

Apresenta como vantagem boa capacidade para retenção de metais pesados como cádmio e chumbo. Dispõe como ponto negativo a maior ocorrência de reações de precipitação na barreira, o que permite que o contaminante permaneça em solução e seja solubilizado na presença de ácido (KORF; PRIETTO, 2011).

\subsubsection{Bentonita aplicada como impermeabilização de base}

A combinação de bentonita e solo local compactado permite a diminuição do coeficiente de condutividade hidráulica e reduz a permeabilidade dos contaminantes presentes no sistema. $\mathrm{O}$ produto entre o solo argiloso compactado e adição de aproximadamente $4 \%$ de bentonita resulta numa barreira impermeabilizante com coeficiente de permeabilidade de $10^{-7} \mathrm{~cm} \cdot \mathrm{s}^{-1}$, atendendo a norma 13.896/97 para aterros com resíduos não perigosos. A utilização desse liner possui como vantagem a diminuição de custos do empreendimento, além da disponibilidade de solos bentoníticos próximos a aterros em diversos pontos do país, como em alguns lugares do Nordeste (ROWE, 2010).

\subsection{Impermeabilização da base}

A camada de impermeabilização da base deve garantir a segura separação da disposição de resíduos do subsolo, impedindo a contaminação do lençol freático e do meio natural através de infiltrações de percolados e/ou substâncias tóxicas. Para desempenhar essa função de maneira eficiente, a camada de impermeabilização deve compor-se de solo argiloso de baixa permeabilidade ou geomembrana sintética com espessuras adequadas (LANZA, CARVALHO, ALVIM, 2005).

$\mathrm{Na}$ aplicação da camada de impermeabilização de base com o emprego de solo argiloso, o fator que determinará o desempenho do sistema é a compactação realizada em campo. Durante os trabalhos é fundamental um rigoroso controle de 
compactação em cada espessura de solo espalhado para verificar se o tratamento da base está de acordo com as especificações definidas no projeto técnico (LANZA, CARVALHO, ALVIM, 2005).

\section{Conclusão}

A impermeabilização do solo em aterros sanitários além de ser uma medida legislativa, é essencial para a proteção do meio ambiente, evita a contaminação das camadas do solo e do lençol freático pelo chorume. $\mathrm{O}$ sistema de impermeabilização possui inúmeras técnicas para que ocorra a proteção do solo de forma eficiente e sem riscos ao meio ambiente. Tais técnicas se enquadram às diversidades de características de áreas onde possam instalar os aterros sanitários que são uma alternativa de baixo custo para o tratamento de rejeitos e resíduos sólidos.

Urge a conscientização da sociedade em relação ao uso dos recursos naturais e sobre reutilização dos resíduos gerados para reduzir de forma gradativa e crescente produção dos mesmos. Reaproveitar o lixo gerado desde a coleta seletiva, separação e reciclagem pode potencializar o tempo de vida útil dos aterros sanitários. Quando o lixo é descartado de maneira incorreta e sem tratamento, pode causar poluição do solo e do meio ambiente, portanto, cuidados primordiais precisam ser tomados para evitar poluição desnecessária que pode ser irreversível e de imensurável prejuízo ao ambiente e aos sistemas agrícolas que necessitam de solo saudável para produção de alimentos.

\section{Referências}

ASSOCIAÇÃO BRASILEIRA DE NORMAS TÉCNICAS - ABNT. NBR 7182: Solo - Ensaio de compactação. Rio de Janeiro: ABNT, 1986. 10p.

ASSOCIAÇÃO BRASILEIRA DE NORMAS TÉCNICAS - ABNT. NBR 13896: Aterros de resíduos não perigosos - Critérios para projeto, implantação e operação. Rio de Janeiro, 1997.

ALMEIDA, F. T. R.; SANTOS, G. O.; SILVA, R. A. C. da; GOMES, C. C. Caracterização física do solo utilizado em camadas de cobertura no aterro sanitário de Caucaia-Ceará. In: CONGRESSO NORTENORDESTE DE PESQUISA E
INOVAÇÃO, 5., Maceió. $\quad$ Anais... Maceió: CONNEPI, 2010.

ALMEIDA, J. R. de; IZZO, R. L. dos S.; MAHLER, C. F. O uso de composto como alternativa de cobertura de aterros. In: CONGRESSO BRASILEIRO DE GEOTECNIA AMBIENTAL, 7., SIMPÓSIO BRASILEIRO DE GEOSSINTÉTICOS, 6., 2011, Belo Horizonte. Anais... Belo Horizonte: REGEO/Geossintéticos, 2011.

BARBERO, D.; MARONI, A.; PEYROT, S. Laboratory Permeability and Single Ring Infiltration Tests for the Testing of Waterproofing Barriers of Landfill Tanks. Journal of Geotechnical Engineering, v. 7, n. 2, p. 29-37, 2020.

BIZARRETA, J. C. O.; DE CAMPOS, T. M. P. Caracterização do lodo de uma estação de tratamento de chorume visando seu emprego em coberturas finais de aterros sanitários. In: CONGRESSO BRASILEIRO DE GEOTECNIA AMBIENTAL, 7 ., SIMPÓSIO BRASILEIRO DE GEOSSINTÉTICOS, 6., 2011, Belo Horizonte. Anais... Belo Horizonte: REGEO/Geossintéticos, 2011.

BOFF, F. E. Estudo da seletividade iônica na interação solo-contaminante aplicado a liners. São Carlos: EESC/USP. Seminário (Seminários Gerais em Geotecnia) -Escola de Engenharia de São Carlos, Universidade de São Paulo, 1998.

BOSCOV, M. E. G. Geotecnia ambiental. $1^{\text {a }}$ Reimp. São Paulo: Oficina de Textos, 2008.

BUENO, B. S.; BENVENUTO, C.; VILAR, O. M. Aplicações em Barreiras Impermeabilizantes: Manual Brasileiro de Geossintéticos. São Paulo: Edgard Blucher, 2004.

CARVALHO, M. F. Comportamento mecânico de resíduos sólidos urbanos. 1999. 330 f. Tese (Doutorado em Geotecnia) - Escola de Engenharia de São Carlos, Universidade de São Paulo, São Carlos, 1999.

CARVALHO, J. C.; GITIRANA JR., G. F. N.; MACHADO, S. L.; MASCARENHA, M. M. A.; SILVA FILHO, F. C. Solos não saturados no contexto geotécnico. São Paulo: Associação Brasileira de Mecânica dos Solos e Engenharia Geotécnica, 2015. 759p.

CATAPRETA, C. A. C. Comportamento de um aterro sanitário experimental: avaliação da influência do projeto, construção e operação. 2008. 316 f. Tese (Doutorado em Saneamento, Meio Ambiente e Recursos Hídricos) - Escola de Engenharia, Universidade Federal de Minas Gerais, Belo Horizonte, 2008. 
CATAPRETA, C. A. A.; SIMÕES, G. F.; SILVEIRA, R. M. B. Execução de camada de cobertura final de aterros sanitários de grande porte - estudo de caso do aterro sanitário de Belo Horizonte. In: CONGRESSO BRASILEIRO DE GEOTECNIA AMBIENTAL, 7., SIMPÓSIO BRASILEIRO DE GEOSSINTÉTICOS, 6., 2011, Belo Horizonte. Anais... Belo Horizonte: REGEO/Geossintéticos, 2011.

ELK, A. G. H. P. Van. Redução de emissões na disposição final. Rio de Janeiro: IBAM, 2007.

EPA - United States Environmental Protection Agency. Ficha técnica dos sistemas de cobertura de evapotranspiração para contenção de resíduos. Washington DC., 2011. 26p.

EPA - UNITED STATES ENVIRONMENTAL PROTECTION AGENCY. Orientação técnica para as capas finais do RCRA / CERCLA. Washington DC., 2004. 421p.

FELDKIRCHER, W. Impermeabilização de Aterros Sanitários com Geomembrana. 2008. 62p. Trabalho de Conclusão de Curso (Engenharia Civil) - Universidade São Francisco, Unidade Acadêmica da Área de Ciências Exatas e Tecnológicas, Itatiba, 2008.

FUNDAÇÃO ESTADUAL DE MEIO AMBIENTE DE MINAS GERAIS - FEAM. Orientações técnicas para a operação de aterros sanitários. Belo Horizonte: FEAM, 2005.

GEOFOCO. Impermeabilização de Aterros Sanitários com Geomembrana de PEAD. Disponível em: $<$ http://www.geofoco.com.br/impermeabilizacaode-aterros-sanitarios-com-geomembrana-de-pead/>

KORF, E. P.; PRIETTO, P. D. M. Comportamento hidráulico e reativo de uma mistura compactada solo-cimento como barreira de contenção de resíduos industriais e de mineração. In: CONGRESSO BRASILEIRO DE GEOTECNIA AMBIENTAL, 7., SIMPÓSIO BRASILEIRODE GEOSSINTÉTICOS, 6., 2011, Belo Horizonte. Anais... Belo Horizonte: REGEO/Geossintéticos, 2011

LANZA, V. C. V.; CARVALHO, A. L.; ALVIM, R. V. Orientações Técnicas para Operação de Aterro Sanitário. Fundação Estadual do Meio Ambiente. Belo Horizonte: FEAM, 2005.

LEME, M. A. G. Caracterização de Solo Utilizado no Sistema de Barreira Impermeabilizante de Base de uma Célula Experimental de Resíduos Sólidos Urbanos. 2013. 208 p. Campinas, SP. Dissertação (Mestrado em Engenharia Civil) Faculdade de Engenharia Civil, Arquitetura e
Urbanismo. Universidade Estadual de Campinas, 2013.

LENGEN, A.; SIEBKEN, J. Geomembrane in the United State: A brief discussion. Nova York: De Groat, Den Hoedt \& Termaat, 1996.

LIMA, L. M. Q. Tratamento de Lixo. São Paulo: Hemus Editora, 1985.

LINS, C. M. M.; NÓBREGA, C. C.; LINS, E. A. M.; SILVA, F. M. S.; NOGUEIRA, G. A. B.; JUCÁ, J. F. T.; BELTRÃO, K. G. Q. de B.; ALVES, M. C. M. Resíduos Sólidos: Projeto, operação e monitoramento de aterros sanitários. Salvador: ReCESA, 2008.

LOCASTRO, J. K.; ANGELIS, B. L. D. de. Barreiras de impermeabilização: configurações aplicadas em aterros sanitários. Revista Eletrônica em Gestão, Educação e Tecnologia Ambiental, Santa Maria, v. 20, n. 1, jan.-abr., p. 200-210, 2016.

LUKIANTCHUKI, J. A; ESQUIVEL, R. E. Estudo do emprego de solo-bentonita como barreira impermeabilizante em aterros sanitários. In: SIMPÓSIO BRASILEIRO DE JOVENS GEOTÉCNICOS - GEO-JOVEM 2006, 2., 2006, Nova Friburgo. Anais... Nova Friburgo, Geojovem, 2006.

MACIEL, F. J.; JUCÁ, J. F. T. Evaluation of landfill gas production and emissions in a MSW large-scale Experimental Cell in Brazil. Waste Management, v. 31, n. 5, p. 966-977, 2011.

MIMIDES, T.; PERRAKI, T. Avaliação das propriedades atenuantes de argilas gregas selecionadas para elementos inorgânicos tóxicos em aterros sanitários. A Ciência do Ambiente Total, v. 253, p.1-13, 2000 .

PAULA, G. S. Investigação das Técnicas de Impermeabilização de Aterros Utilizadas no Estado Do Paraná. 2017. 59 p. Trabalho de Conclusão de Curso (Engenharia Cicil) Universidade Tecnológica Federal do Paraná, Campo Mourão, 2017.

PIEDADE JÚNIOR, C. R. C. Análise da potencialidade de alguns solos não lateríticos para utilização em barreiras impermeáveis. 2003. 124 f. Dissertação (Mestrado em Geotecnia). Escola de Engenharia de São Carlos, Universidade de São Paulo, São Carlos, SP, 2003.

PIMENTEL, K. C. A.; PALMEIRA, E. M. Reabilitação de barreiras impermeabilizantes com geossintéticos. In: CONGRESSO BRASILEIRO DE GEOTECNIA AMBIENTAL, 7., SIMPÓSIO BRASILEIRO DE GEOSSINTÉTICOS, 6., 2011, Belo Horizonte. Anais... Belo Horizonte: REGEO/Geossintéticos, 2011. 
ROWE, R. K. Manual de Engenharia Geotécnica e Geoambiental. Editores Acadêmicos da Klwer, 2010.

SPAGNOLI, G.; CLEMENT, F.; DILNESA, B.; CAO, F.; FENG, P. A new waterproofing membrane for tailings ponds. In: INTERNATIONAL CONFERENCE ON PASTE, THICKENED AND FILTERED TAILINGS， 22., 2019, Perth. Proceedings... Perth: Australian Centre for Geomechanics, 2019. p. 153-164. Disponível em: https://papers.acg.uwa.edu.au/p/1910_08_Spagnoli

TRÍGONO ENGENHARIA. Projeto Executivo Aterro Sanitário de Campo Mourão - PR. Campo Mourão, 1999.
VERTEMATTI, J. C. Manual Brasileiro de Geossintéticos. ABINT. São Paulo, Brasil, 2004

VISENTIN, C.; ZANELLA, P.; KRONHARDT, B.; DA SILVA TRENTIN, A.; BRAUN, A.B.; THOMÉ, A. (2019). Use of geosynthetic clay liner as a waterproofing barrier in sanitary landfills. Journal of Urban and Environmental Engineering. v. 13, n. 1, p. 115-124, 2019.

WORKMAN, J. P.; KEEBLE, R. L. Design and construction of liner systems. In: CHISTENSEN, T. H.; COSSU, R.; STEGMANN, R. Sanitary Landfilling: Process, Technology and Environmental Impact. London: Academic Press, 1, 1989. 